\title{
Traditional Mediterranean diet and longevity in the elderly: a review
}

\author{
Antonia Trichopoulou* $\dagger$ \\ Department of Hygiene and Epidemiology, School of Medicine, University of Athens, 75 M. Asias Street, GR-1 15 27, \\ Athens, Greece
}

\begin{abstract}
Objective: To review the evidence that the traditional Mediterranean diet is associated with longevity.

Setting: Elderly persons of both genders in Greece, Spain, Denmark and Australia studied by different groups of investigators.

Methods: Adherence to the principles of the Mediterranean diet was operationalised through a score devised $a$ priori, and study participants were followed up until death or the end of the study. Proportional hazard models were used.

Results: Closer adherence to the Mediterranean diet was associated with a significant decrease in general mortality among the elderly persons studied.

Conclusion: The Mediterranean diet is positively associated with longevity among the elderly. If the assumption holds that there is no interaction between age and diet with respect to general mortality, it can be inferred that the traditional Mediterranean diet represents a healthy nutritional pattern.
\end{abstract}

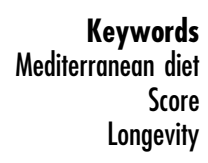

The Mediterranean culture, more than most others, integrates the past and the present. Some 20 countries can be thought of as Mediterranean. Their populations vary in culture, ethnicity, religion, economic development and other factors that can influence dietary intake. But the dietary patterns that prevail in the Mediterranean region have many common characteristics. Most of them stem from the fact that olive oil occupies a central position. We could define the Mediterranean diet as the dietary pattern found in olive-growing areas of the Mediterranean region in the late 1950s and early 1960s, when the consequences of World War II were overcome, but fast-food culture had not yet reached the area.

Keys and his colleagues were the first to hypothesise that the traditional Mediterranean diet has beneficial effects on a range of diseases, and they provided ecological evidence in support of their hypothesis with respect to coronary heart disease (CHD). More recent papers, which evaluated the evidence accumulated over the years, have indicated that the traditional Mediterranean diet meets several important criteria for a healthy diet.

Direct evidence in support of the beneficial properties of the Mediterranean diet has also become available. These data derive from four studies, which have used a diet score devised a priori on the basis of eight desirable key features of the traditional common diet in the Mediterranean region.

†Recipient of the IV Grande Covian Award.
The traditional Mediterranean diet may be thought of as having eight components:

1. High ratio of monounsaturated to saturated dietary lipids (mainly olive oil);

2. Moderate ethanol consumption;

3. High consumption of legumes;

4. High consumption of non-refined cereals, including bread;

5. High consumption of fruits;

6. High consumption of vegetables;

7. Low consumption of meat and meat products;

8. Moderate consumption of milk and dairy products.

Fish intake is also a desirable characteristic of the Mediterranean diet, but has depended on the proximity to the sea.

In these studies, it was hypothesised that a diet with more of these components has beneficial effects, whereas a diet with fewer of these components would be less healthy. These assumptions were based on the collective epidemiological and biological evidence.

\section{The Greek study}

In the first study ${ }^{1}$, data collected in three Greek villages provided the opportunity to evaluate prospectively the role of diet in the survival of elderly Greeks. The data were collected from 182 elderly residents, as part of an international cross-cultural study of food habits in later life. Diet was assessed with a validated, extensive, 
semi-quantitative questionnaire on food intake. A one-unit increase in the previously indicated score, rising from zero (bad) to 8 (excellent), was associated with a significant $17 \%$ reduction in overall mortality. This study provided the first direct evidence that the Mediterranean diet favourably affects life expectancy, at least among elderly people.

\section{The Danish study}

Results of studies of Mediterranean diet in Mediterranean populations may, however, be confounded by the likely association of adult diet with early-life nutritional patterns and culture-specific psychosocial variables like social support. Yet a study performed in Denmark ${ }^{2}$ provided similar results.

This study examined the association of a Mediterranean dietary pattern with total mortality in a cohort of elderly people living in a northern European community. Diet and nutritional status were studied among 202 elderly men and women born between 1914 and 1918 and living in a Danish municipality in 1988. They were followed for 6 years. A diet score, with seven dietary characteristics of the Mediterranean diet, was associated with a significant reduction in overall mortality. A one-unit increase in the diet score was associated with a significant $21 \%$ reduction in mortality. The authors concluded that the Mediterranean diet score predicts survival even in a northern European population.

\section{The Australian study}

A study ${ }^{3}$ was undertaken in Melbourne, Australia, among elderly Anglo-Celts and Greek Australians, with two objectives:

- To examine whether the results from the studies in rural Greece and Denmark could be replicated in an urban setting in Australia;

- To examine whether the apparent benefits of the Mediterranean diet are transferable to population groups with very different dietary habits, like the Anglo-Celts.

This study involved 141 Anglo-Celts and 189 Greek Australians of both genders aged 70 years or more. The researchers evaluated whether adherence to the principles of a Mediterranean diet affects the survival of elderly people in a non-Mediterranean country. A one-unit increase in the diet score was again associated with a $17 \%$ reduction in overall mortality. Mortality reduction with increasing diet score was at least as evident among Anglo-Celts as among Greek Australians.

\section{The Spanish study}

A study ${ }^{4}$ was also undertaken in Spain to examine the Mediterranean diet in relation to overall survival among institutionalised, elderly non-smokers. One hundred and sixty-one Spanish non-smokers of both genders, aged 65 years or more, were followed for 9 years. A one-unit increase in the eight-unit Mediterranean diet score was again associated with a significant $31 \%$ reduction in mortality among elderly subjects, although the effect was evident only among persons younger than 80 years.

\section{What is the best diet?}

So, what is the best diet? Most of our existing knowledge, translated into various guidelines or recommendations, relies on associations between food groups, foods and nutrients on one hand, and incidence of specific diseases on the other, mainly with respect to the two most common categories of diseases: cardiovascular disease and cancer. The health effects of overall dietary patterns may be of critical importance, but until recently there has been no simple way to adequately harvest the dietary pattern information in an epidemiological investigation ${ }^{5}$.

The conclusion of these four studies, however, was that a diet that adheres to the principles of the traditional Mediterranean one is associated with longer survival. The use of dietary patterns could be a powerful tool towards our conceptualisation of the role of diet in chronic diseases.

The Mediterranean diet is dominated by the consumption of olive oil and by high consumption of vegetables and fruits $^{6}$. The data in Figs 1 and 2 were retrieved from the DAFNE (DAta Food NEtworking) food databank and present the disparity in the added lipids (including olive oil) and vegetable consumption among 10 European countries.

It is evident that Greece and Spain are the two countries where the consumption of olive oil and vegetables is particularly high.

In Greece, but probably in other Mediterranean areas as well, the consumption of vegetables includes various wild greens, which are traditionally collected throughout the country and consumed in various ways. They are usually prepared with virgin olive oil. The wild edible greens eaten frequently in rural areas in the form of salads and pies contain very high quantities of flavonoids, which are generally considered one of the most important categories of antioxidant in the human diet $^{7}$. It is worthwhile to note that wild greens have a considerably higher flavonoid content than an equal quantity of red wine or black tea, which are considered principal sources of flavonoids for northern European countries.

\section{Supporting biological evidence}

Biochemical, clinical and epidemiological research has provided a solid biological foundation for the health benefits of the Mediterranean diet. It has been established that moderate drinking of alcoholic beverages reduces the risk of CHD, probably by increasing levels of serum highdensity lipoprotein (HDL) cholesterol $^{8-10}$. Moderate 


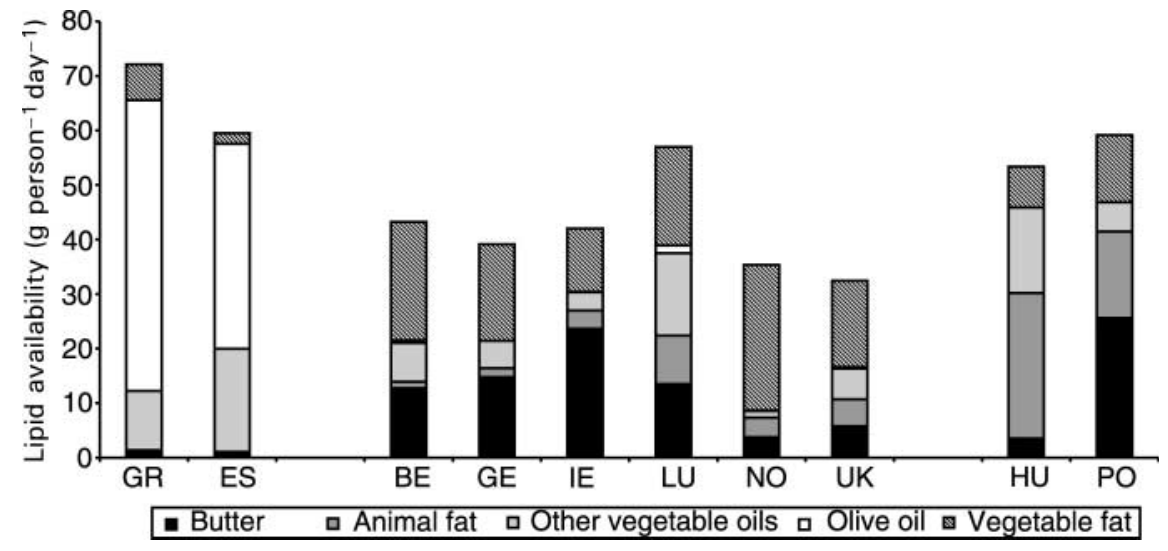

Fig. 1 Average total added lipid availability $\left(\mathrm{g}_{\text {person }}{ }^{-1}\right.$ day $^{-1}$ ) by type, in 10 DAFNE countries circa 1990. DAFNE - DAta Food NEtworking; GR - Greece; ES - Spain; BE - Belgium; GE - Germany; IE - Ireland; LU - Luxembourg; NO - Norway; UK - United Kingdom; HU - Hungary; PO - Poland

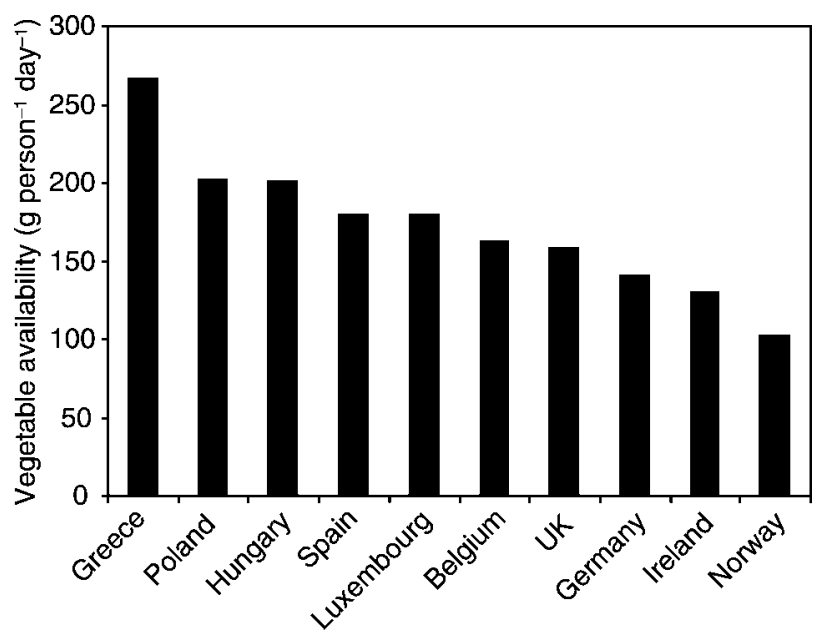

Fig. 2 Average vegetable availability $\left(\mathrm{g}_{\text {person }}{ }^{-1}\right.$ day $\left.^{-1}\right)$ in 10 DAFNE countries, circa 1990. DAFNE - DAta Food NEtworking

consumption of wine, as a rule during meals, is a characteristic of the Mediterranean diet. Perhaps more important, it has now been established that monounsaturated lipid, mostly from olive oil, increases HDL cholesterol more than does polyunsaturated lipid and substantially more than do carbohydrates, making it an optimal energy-generating nutrient ${ }^{11}$.

There is also powerful evidence that consumption of vegetables and fruits reduces the risk of most forms of cancer $^{12}$. High consumption of vegetables and fruits is typical in the Mediterranean diet and helps to explain the relatively low incidence of several forms of cancer in the Mediterranean region. In addition, recently accumulated evidence on the deleterious role of plasma homocysteine levels on CHD risk provides an additional foundation for the inverse association between the consumption of vegetables, on the one hand, and CHD and peripheral arterial disease, on the other ${ }^{13-17}$. Homocysteine levels are reduced by folic acid found mainly in vegetables.
In addition to the indicated established biological processes that help to explain the beneficial effects of the Mediterranean diet, several others are currently being investigated, mainly in relation to olive oil. Thus, there is converging evidence that olive oil conveys protection against breast cancer ${ }^{18}$. There are also findings that olive oil may reduce the risk of some forms of dementia ${ }^{19}$ and perhaps of endometrial and ovarian cancer. Vitamin E, which exists in abundance in olive oil, has been reported to reduce the risk of $\mathrm{CHD}^{20}$, and diets rich in monounsaturated fatty acids have broad beneficial effects on plasma lipoproteins ${ }^{21}$. A recent study indicates that monounsaturated lipid, mostly from olive oil, is associated with a significant decrease in the risk of sporadic colorectal cancer with wild-type ki-ras genotype ${ }^{22}$.

Olive oil and complex carbohydrates derived from legumes, whole-wheat bread and cereals, all plentiful in the Mediterranean diet, are only weakly conducive to postprandial hyperglycaemia, which is implicated in the pathogenesis of diabetes mellitus ${ }^{23,24}$. Monounsaturated lipids derived from olive oil have been reported to increase bone mineral density and reduce the risk of osteoporosis $^{25}$.

Longevity linked to quality of life is the goal for a productive and successful ageing. Nutrition and diet have not been part of mainstream research on quality of life. Nevertheless, there is some evidence that an important element of the Mediterranean diet, that is olive oil, may contribute to the preservation of cognitive function and physical performance in old age ${ }^{19}$.

\section{From science to policy}

The Mediterranean diet needs to be promoted assertively in Mediterranean countries, as well as elsewhere. When the objective is to promote the healthy traditional Mediterranean diet to Mediterranean people, science is supported by tradition and culture. After almost half a century of 


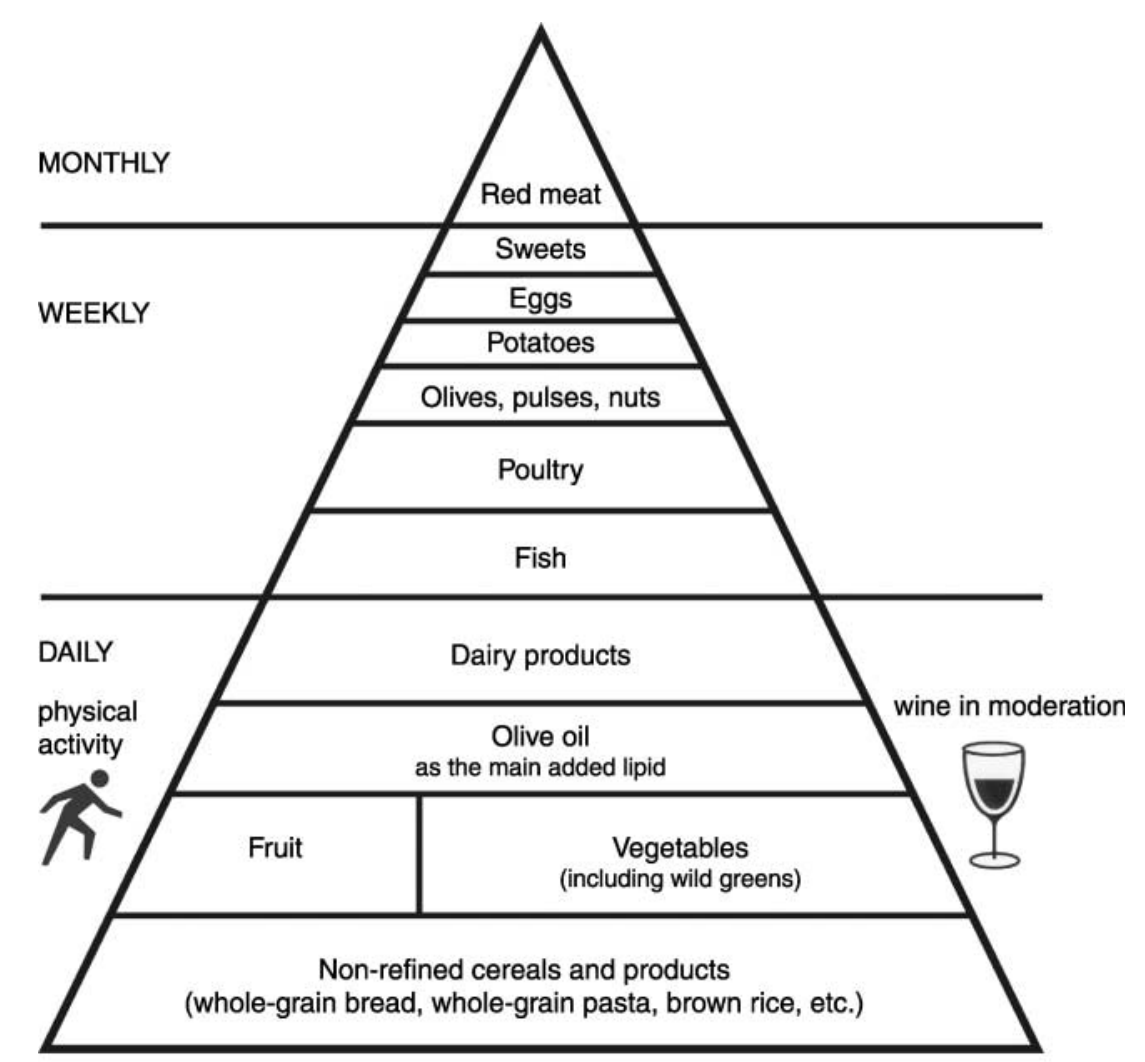

Also remember to :

- drink plenty of water

- avoid salt and replace it by hernbs (e.g oregano, basil, thyme, etc.)

commercial pressures on the Mediterranean people to change their nutritional lifestyle, they have to be reassured that they used to have one of the best dietary patterns. In addition, practical steps need to be taken, starting with mass catering establishments. Governmental institutions, such as schools, hospitals and the army, should base their menus on the Mediterranean tradition. Moreover, an infusion of glamour is needed and here one could learn from the advertising companies. Official dinners and receptions should honour our Mediterranean traditions and the Mediterranean diet pyramid (Fig. 3) should be actively promoted ${ }^{26}$.

\section{Conclusion}

It is not certain that the Mediterranean diet can fully explain the good health of Mediterranean people, but it appears unquestionable that it contributes to it. It has been argued that the relaxing psychosocial environment in most Mediterranean countries, and preservation of the habit of an extended family structure, may also play contributory roles. These influences, however, are still integral parts of our Mediterranean traditions, and their preservation could also help the preservation of the Mediterranean diet itself.

\section{Acknowledgements}

My husband and I are deeply honoured for being presented with the IV Grande Covian Award. Indeed, this is one of the most important and happy moments of our common professional life.

I was fortunate to interact with Professor Grande Covian on several occasions. Perhaps the most cherished memories are from his visit with Madame Covian to Athens in 1986. He contributed with his passionate and deeply scientific approach to the resurgence of the Mediterranean diet in Greece.

We are the fortunate ones to receive this Grande Covian Award. But the honour belongs to many in the nutrition community for developing the scientific evidence that the Mediterranean diet represents not only a healthy diet, but also a diet that expresses a rich cultural heritage.

\section{References}

1 Trichopoulou A, Kouris-Blazos A, Wahlqvist ML, Gnardellis C, Lagiou P, Polychronopoulos E, et al. Diet and overall 
survival in elderly people. British Medical Journal 1995; 311: $1457-60$.

2 Osler M, Schroll M. Diet and mortality in a cohort of elderly people in a north European community. International Journal of Epidemiology 1997; 26: 155-9.

3 Kouris-Blazos A, Gnardellis C, Wahlqvist ML, Trichopoulos D, Lukito W, Trichopoulou A. Are the advantages of the Mediterranean diet transferable to other populations? A cohort study in Melbourne, Australia. British Journal of Nutrition 1999; 82: 57-61.

4 Lasheras C, Fernandez S, Patterson AM. Mediterranean diet and age with respect to overall survival in institutionalized, nonsmoking elderly people. American Journal of Clinical Nutrition 2000; 71: 987-92.

5 Trichopoulos D, Lagiou P, Trichopoulou A. Evidence-based nutrition. Asia Pacific Journal of Clinical Nutrition 2000; 9(Suppl.): S4-9.

6 Trichopoulou A, Naska A, Vasilopoulou E. Guidelines for the intake of vegetables and fruit: the Mediterranean approach. International Journal for Vitamin and Nutrition Research 2001; 71(3): 149-53.

7 Hertog MGL, Krombout D, Aravanis C, Blackburn H, Buzina $\mathrm{R}$, Fidanza $\mathrm{F}$, et al. Flanovoid intake and long-term risk of coronary heart disease and cancer in the Seven Countries Study. Archives of Internal Medicine 1995; 155: 381-6.

8 Rimm EB, Klatsky A, Grobbee D, Stampfer MJ. Review of moderate alcohol consumption and reduced risk of coronary heart disease: is the effect due to beer, wine, or spirits? British Medical Journal 1996; 312: 731-6.

9 Gaziano JM, Buring JE, Breslow JL, Goldhaber SZ, Rosner B, VanDenburgh $\mathrm{M}$, et al. Moderate alcohol intake, increased levels of high-density lipoprotein and its subfractions and decreased risk of myocardial infarction. New England Journal of Medicine 1993; 329: 1829-34.

10 Ridker PM, Vaughan DE, Stampfer MJ, Glynn RJ, Hennekens $\mathrm{CH}$. Association of moderate alcohol consumption and plasma concentration of endogenous tissue-type plasminogen activator. Journal of the American Medical Association 1994; 272: 929-33.

11 Mensink RP, Katan MB. Effect of dietary fatty acids on serum lipids and lipoproteins: a meta-analysis of 27 trials. Arteriosclerosis and Thrombosis 1992; 12: 911-9.

12 World Cancer Research Fund (WCRF)/American Institute for Cancer Research (AICR). Food, Nutrition and the Prevention of Cancer: A Global Perspective. Washington, DC: WCRF/AICR, 1997.

13 Kromhout D, de Lezenne C. Diet, prevalence and 10-year mortality from coronary heart disease in 871 middle-aged men: The Zutphen Study. American Journal of Epidemiology 1984; 119: 733-41.

14 Rimm EB, Ascherio A, Giovannucci E, Spiegelman D, Stampfer MJ, Willett WC. Vegetable, fruit, and cereal fiber intake and risk of coronary heart disease among men.
Journal of the American Medical Association 1996; 275 : 447-51.

15 Farchi G, Fidanza F, Mariotti S, Menotti A. Is diet an independent risk factor for mortality? 20 year mortality in the Italian rural cohorts of the Seven Countries Study. European Journal of Clinical Nutrition 1994; 48: 19-29.

16 Stampfer MJ, Malinow MR, Willett WC, Newcomer LM, Upson B, Ullmann D, et al. A prospective study of plasma homocyst(e)ine and risk of myocardial infarction in US physicians. Journal of the American Medical Association 1992; 268: 877-81.

17 Arnesen E, Refsum H, Bonaa KH, Ueland PM, Forde OH, Nordrehaug JE. Serum total homocysteine and coronary heart disease. International Journal of Epidemiology 1995; 24: 704-9.

18 Trichopoulou A. Olive oil and breast cancer. Cancer Causes \& Control 1995; 6(6): 475-6.

19 Solfrizzi V, Panza F, Torres F, Mastroianni F, Del Parigi A, Venezia A, et al. High monounsaturated fatty acids intake protects against age-related cognitive decline. Neurology 1999; 52(8): 1563-9.

20 Kushi LH, Lenart EB, Willett WC. Health implications of Mediterranean diets in light of contemporary knowledge. 2. Meat, wine, fats and oils. American Journal of Clinical Nutrition 1995; 61(Suppl.): 1416S-27S.

21 Berry EM, Eisenberg S, Friedlander Y, Harats D, Kaufmann NA, Norman Y, et al. Effects of diets rich in monounsaturated fatty acids on plasma lipoproteins - the Jerusalem Nutrition Study: monounsaturated vs saturated fatty acids. Nutrition, Metabolism, and Cardiovascular Diseases 1995; 5: 55-62.

22 Bautista D, Obrador A, Moreno V, Cabeza E, Canet R, Benito $\mathrm{E}$, et al. Ki-ras mutation modifies the protective effect of dietary monounsaturated fat and calcium on sporadic colorectal cancer. Cancer Epidemiology, Biomarkers \& Prevention 1997; 6: 57-61.

23 Jeppesen J, Chen YD, Zhou MY, Wang T, Reaven GM. Effect of variations in oral fat and carbohydrate load on postprandial lipemia. American Journal of Clinical Nutrition 1995; 62: 1201-5.

24 Jeppesen J, Schaaf P, Jones G, Zhou MY, Chen YDI, Reaven GM. Effects of low-fat, high-carbohydrate diets on risk factors for ischemic heart disease in postmenopausal women. American Journal of Clinical Nutrition 1997; 65(4): 1027-33.

25 Trichopoulou A, Georgiou E, Bassiakos Y, Lipworth L, Lagiou P, Proukakis C, et al. Energy intake and monounsaturated fat in relation to bone mineral density among women and men in Greece. Preventive Medicine 1997; 26: 395-400.

26 Supreme Scientific Health Council, Ministry of Health and Welfare of Greece. Dietary guidelines for adults in Greece. Archives of Hellenic Medicine 1999; 16: 516-24. 